\title{
History of Natural Diamond Formation Based on Defect Characteristics Detected by Spectroscopic Methods
}

\author{
L.I. Tretiakova ${ }^{1}$, A.M. Lyukhin ${ }^{2}$ \\ ${ }^{1}$ St. Petersburg Branch Russian Mineralogical Society, RUSSIA, ltretia@gmail.com \\ ${ }^{2}$ Institute of remote ore prognosis, Moscow, RUSSIA, alex.lyukhin@gmail.com
}

\section{Introduction}

The history of natural gem diamond formation that genetically related with impact events followed by shock, progressive and regressive metamorphism of target rock areas has been deduced by data obtained by complex nondestructive spectroscopic methods: Raman spectroscopy, PLS, CLS, IRS and also mineralogical and literature data. About 200 representative natural gem diamonds have been picked out from investigated thousands samples: colorless, yellow, brown colors, $0.03-1.60$ carat weight, zoning with cubic internal morphology of crystal centers graduated to cubo-octahedral and octahedral forward to intermediate and rim zones, mineral inclusions in central zones were represented by tiny inclusions of graphite, $\propto-\mathrm{Fe}, \mathrm{Ni}-\mathrm{Fe}$, sulfides etc., intermediate - by peridotitic, eclogitic and UHP minerals, often surrounded by discoid fractures and melt inclusions; rim zones association of secondary minerals and gas/fluid inclusions. Diamond zones were differentiated by $\mathrm{C}$ and $\mathrm{N}$ isotopic compositions and also $\mathrm{N}$ content and $\mathrm{N}$ aggregation state. All diamond crystals had dislocations, plastic deformation, discoid fractures around inclusions and birefringence.

\section{UHP-HT features of natural diamonds}

1. The presence of $s p^{1} \rightarrow s p^{2} \leftrightarrow s p^{3}$ carbon phase transformations (Fig.1), including diamond $\leftrightarrow$ lonsdaleite transformation that has been completed in nanoseconds under a shock wave compression of cubic diamond [He, 2002]. Lonsdaleite line maximum in Raman spectra is the 1324.4 см-1 $(552.2 \mathrm{~nm})$.

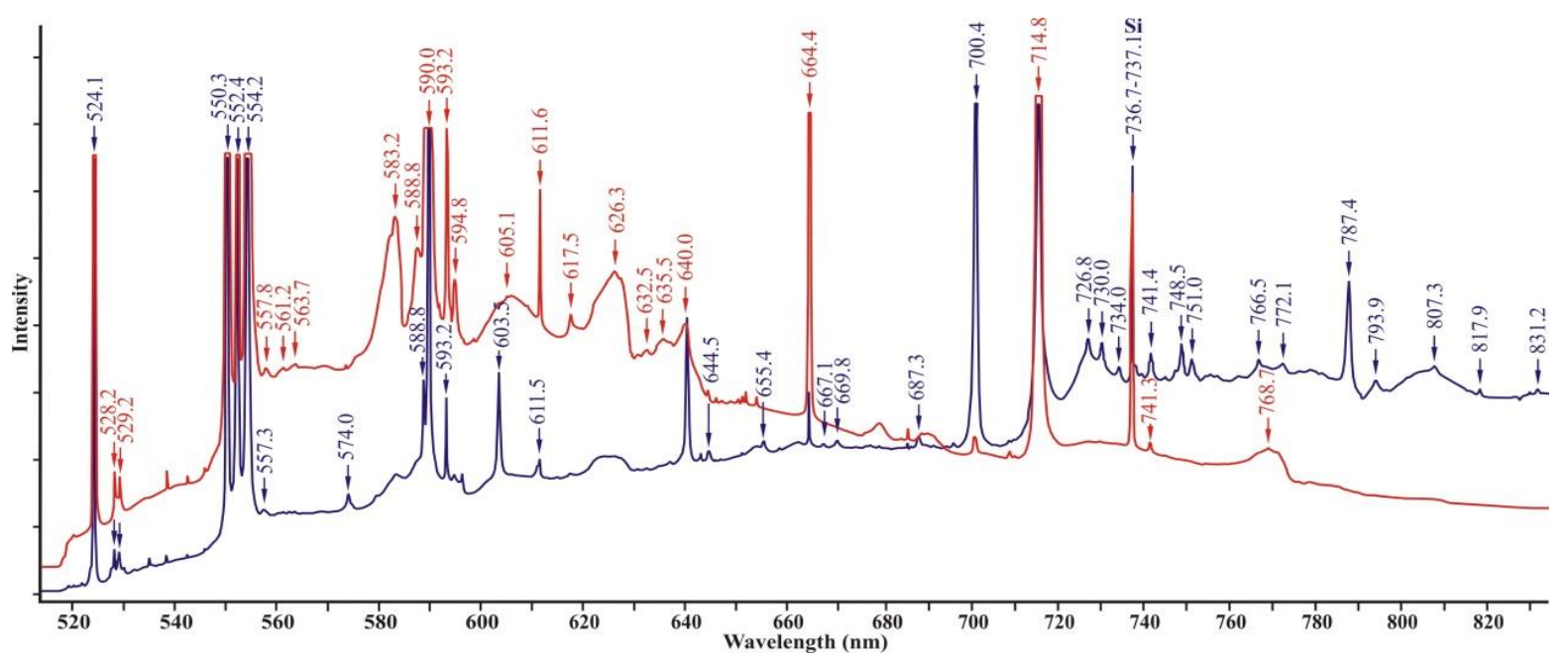

Fig. 1. PLS ( $\lambda$ exc $514.5 \mathrm{~nm}$ ) IaAB (regular) diamond. Strong lines in range 550.3-552.4 nm $-s p^{2} \leftrightarrow s p^{3}$ carbon phase transformations [Zaitsev, 2001]; 554.2-554.7 nm $-s p^{I} \rightarrow s p^{2} \rightarrow s p^{3}$ primary carbon matter transformations by shock wave [Miyamoto, 1993]; 583.2-594.8 nm - superposition of II order Raman lines and radiation defects; 524.1, 664.4, $714.8 \mathrm{~nm}$ lines identified radiation damage [Zaitsev, 2001]; 605.1- 640-700.4, 787.4, 793.9 nm - Ni-N defects, 669.8 - Co-N defect [Yelisseyev., Kanda, 2007]; 528.2 nm-Si--defects, 736.7-737.1 [Si-V]- defect [Clark et al., 1995]. These defects formed at different PT conditions and preserved in natural diamonds have different temperature formations: $s p^{1} \rightarrow s p^{2} \rightarrow s p^{3}$ carbon phase transformations $>2500 \mathrm{~K}, \mathrm{Ni}-\mathrm{N}$ 2500-1600 K, Co-N 1850-1750 K, [Si-V]- 2200-1200-800 K, and radiation damage $1000-800 \mathrm{~K}$. 
2. Raman line in studied natural diamonds represented intensive positive or negative asymmetric line with maximum1332.5 $\mathrm{cm}^{-1}$, and FWHM in the range $3.2 \mathrm{~cm}^{-1}$ to $9 \mathrm{~cm}^{-1}$ (as a result of HPHT environment conditions) and $\gg 4.5 \mathrm{~cm}^{-1}$ to very large width (HPHT + radiation damage conditions).

3. UHP mineral inclusions in diamonds: diamond $\leftrightarrow$ lonsdaleite, coesite, $\mathrm{SiC}$ and its various modifications, majorite, ringwoodite, TAPP, perovskite and etc. Protogenetic central nano-inclusions, appeared to be diamond seeds, its mineral compositions are carbon phases with $\mathrm{He}, \mathrm{Ar}, \mathrm{Ne}, \mathrm{Xe}, \mathrm{H}_{2}$, $\mathrm{N}_{2}, \mathrm{CO}_{2}, \mathrm{CO}, \mathrm{H}_{2} \mathrm{O}, \mathrm{CH}_{4}$ gases, REEs, $\mathrm{Fe}, \mathrm{Cu}, \mathrm{Cr}, \mathrm{Au}, \mathrm{Ag}$ and etc.; $\mathrm{Ni}, \mathrm{Fe}, \mathrm{Co}, \mathrm{Cu}, \mathrm{Zn}$ sulfides etc.; $\mathrm{Fe}-\mathrm{Cr}$, Fe-Cr-Ti, Fe-Cr-Ni, FeC, oxides $\mathrm{Mg}$, Ti, Pb, Ba. All nano-inclusions are minerals extraterrestrial origin [Rubin, 1997].

4. Variety of crystal structure defects, dislocations, plastic deformations, discoid fractures around inclusions, birefringence, mosaic structures.

\section{Carbon, nitrogen, hydrogen, noble gas sources in natural diamonds}

Nano-diamonds from chondritic meteorites, micro-meteorites, IDPs indicating that they formed outside our solar system and reflecting the conditions in interstellar space, solar nebula and host meteorites [Huss, 2005]. They were the sources of carbon, nitrogen, hydrogen, noble gases in earth's diamonds. ${ }^{13} \mathrm{C}$ value in kimberlitic diamond varied in the range $(-41 \%$ o to $+5.0 \%)$ [Cartigny, 2005]. Value $\delta^{13} \mathrm{C}$ eclogitic and micro-diamonds are nearly to value $\delta^{13} \mathrm{C}(-31$ to $-38 \%)$ similar to extraterrestrial nano-diamonds. Variety of $\mathrm{C}$ modifications and its isotope compositions allow to assume a derivation of different diamond groups from various or mixed carbon sources reflected host rocks (target + impactor) composition. Most part $\mathrm{C}$ - and $\mathrm{N}$ - containing phases in carbonaceous chondrites are organic matter, which is characterized by high $\mathrm{D} / \mathrm{H}$ ratio, value $\delta \mathrm{D}(+300$ to $+1600 \%$ o) [Remusat, 2015].

Dawson (1980) wrote: "Nitrogen exists in platelets and segregated nodes within diamond which is the only site of upper-mantle nitrogen known at present. Whereas some evidence, albeit scanty, exists for a source of carbon and phosphorus, the initial source of the nitrogen and other rare gases within diamond must remain an enigmal". There is only one answer of this enigma: $\mathrm{C}, \mathrm{N}, \mathrm{H}$, noble gases have extraterrestrial nature. $\mathrm{N}$ is widely distributed in Universe and present in diamonds and matrix of chondritic meteorites, micro-meteorites, IDPs, asteroids, comets as variety molecules, including organic. Interstellar organic matter has anomalies of $\mathrm{H}$ and $\mathrm{N}$ isotope, that suggesting of its derivation in presolar molecular clouds or protoplanet disk. [Remusat, 2015]. Values $\delta^{15} \mathrm{~N}(-25$ to $+20 \%)$ are in kimberlite diamonds and $\delta^{15} \mathrm{~N}(+5.3$ to $+25 \%)$ in micro-diamonds from Kumdy-Kol deposit.

Signatures of noble gases $\mathrm{He}, \mathrm{Ne}, \mathrm{Ar}, \mathrm{Kr}, \mathrm{Xe}$ in meteoritic and comet matter preserved in natural diamonds. $3 \mathrm{He}$ is original galactic component have been trapped outside our Solar System [Huss, 2005]. Value ${ }^{3} \mathrm{He} /{ }^{4} \mathrm{He}$ in natural diamonds varied in the range $(7 \times 10-1-8 \times 10-9 \%)$ [Shukoljukov et al., 1996]. 4He, $\mathrm{Ne}$, $\mathrm{Ar}$ и Xe have radiogenic origin, ${ }^{40} \mathrm{Ar}$ and ${ }^{21} \mathrm{Ne}$ joined to diamond seeds during their formation in the space. Noble gases can identify by PL spectra: $\mathrm{He} \sim 523,536.6, \sim 562, \mathrm{Ne}^{+}-$ 716, 719.5 $\mathrm{Xe}^{+}-811.6,793.3, \mathrm{D}\left(\mathrm{H}^{+}\right)-555.0 \mathrm{~nm}$ lines [Zaitsev, 2001].

\section{Transition metals - Ni, Co, $\mathrm{Cr}, \mathrm{Ti}, \mathrm{Fe}$ - and $\mathrm{Si}$ in natural diamonds}

Transition metal defects were observed by PLS in studied diamonds mixed type $1 \mathrm{~b}+\mathrm{IaAB}$ (regular and irregular) with various $\mathrm{N}$ and $\mathrm{H}$ concentrations:

$(\mathrm{Co}-\mathrm{N})$-the $519.7-521.1-523.4,542.5,544.1,623.5 \mathrm{~nm}$ and Co-C $-669.4 \mathrm{~nm}$ systems [Tretiakova 2010] Temperature formation of these defects in the range $\sim 1850-1750 \mathrm{~K}$.

(Ni-N) defects -the S1, S2, S3, 535.2, 694.3-692.4, 603.6, 640.5, 700.6, 787.6, $795.3 \mathrm{~nm}$ are complex interstitial defects with various number $\mathrm{N}$ atoms [Yelisseyev, Kanda, 2007] were formed at temperature range $\sim 2200$ до $\sim 1600 \mathrm{~K}$.

$\mathrm{Cr}^{3+}$ center characterized of $\mathrm{R}_{1} 693.7 \mathrm{~nm}$ and $\mathrm{R}_{2} 692.2 \mathrm{~nm}$ lines in PLS.

Ti-defects the 973.2 and 991.8-1014 (replica) nm, the $991.8 \mathrm{~nm}$ center (Ti-Ti bonds) were observed in natural IIa type diamonds in PLS at first time by authors. Formations temperature of the 973.2 and 993.2-1014.1 nm defects 1900-1800 K and $1600 \mathrm{~K}$, respectively. 
Fe. Most of natural diamonds are magnetic susceptibility, that due iron presence as Fe-magnetic impurity in nano-and submicron diamonds and fluid inclusions, which size $\sim$ equal or less $\lambda$ light, doing them invisible under optic research; $\alpha-\mathrm{Fe}, \mathrm{Fe}_{3} \mathrm{C}$ и $\mathrm{Fe}_{\mathbf{x}} \mathrm{N}$ phases/inclusions are known in meteorites and "central inclusions" in natural diamonds.

Si-defects $-528.2 \mathrm{~nm},[\mathrm{Si}-\mathrm{V}]^{\mathrm{O}}-\sim 946-948 \mathrm{HM}$, and $[\mathrm{Si}-\mathrm{V}]^{-}=736.7-737.1 \mathrm{~nm}$ that formed at $\sim 2200-$ $1200-800 \mathrm{~K}$.

\section{Conclusion}

All of above are evidences of impact events that were provoked diamond generation from carbon matter, delivered by meteoroids and followed diamond growth at shifting HPHT (sharp drop pressure and gradually decreased temperature) conditions corresponding of shock, progressive and regressive metamorphism with metasomatic alterations of impact area rocks.

So, natural diamonds generated and grown in solution-melts due to collision any meteoroid and the Earth followed by shock, progressive and regressive metamorphism in target rock areas. Protogenetic central inclusions in diamond represented by meteoritic minerals and appear to be diamond seeds, early diamond growth started at HPHT conditions by growth scheme HPHT synthetic diamonds; subsequent growth under lower PT conditions came by CVD growth scheme. Sources of C, N, H, noble gases had cosmic origin.

Simultaneous presence in PLS of single natural diamond (Fig.1) defects, formed and preserved at different PT conditions, demonstrate their different temperature formations $s p^{1} \rightarrow s p^{2} \rightarrow s p^{3}$ carbon phase transformations $>2500 \mathrm{~K}, \mathrm{Ni}-\mathrm{N} \sim 2500-1600 \mathrm{~K}, \mathrm{Co}-\mathrm{N} \sim 1850-1750 \mathrm{~K}, \mathrm{Si} \sim 2200-1200-800$ $\mathrm{K}$, radiation damage $\sim 1000-800 \mathrm{~K}$ defects and suggest long diamond history during gradually changing HPHT conditions.

Diamond varieties (from gem stones to carbonado) occurred in one diamond deposit due conditions that took place during these events. Kimberlite pipes and dykes were formed under closer to vertical diamondiferous asteroid impacts to the Earth [Lyukhin, 2008]. At oblique impact diamantiferous asteroid, diamond dispersed on extended territories and later concentrated in placers. Deposits of "metamorphic" diamonds formed under oblique impacts as well. Every kimberlite pipe, every placer and metamorphic deposit of natural diamonds are especially individual under all its parameters.

\section{References}

Cartigny P (2005) Stable isotopes and the origin of diamond. Element (1):79-84

Clark C D, Kanda H, Kiflawi I, Sittas G (1995) Silicon defects in diamond. Physical Review B 51(23): 16681-16688

He H, Sekine T, Kobayashi T (2002) Direct transformation of cubic diamond to hexagonal diamond. Applied Physics Letter 81(4): 610-612

Huss GR (2005) Meteoritic nanodiamonds: messengers from the stars. Elements (1): 97-100

Lyukhin A (2008) The Hypothesis of Impact Origin of Diamonds and Kimberlites. 9-th International Kimberlite Conference, Frankfurt, Germany: Extended. Abstract 9IKC-080

Miyamoto M, Takase T, Mitsuda Y (1993) Raman spectra of various diamonds. Mineralogica Journal, Japan16( 5):246-257

Remusat L (2015) Organic in primitive meteorites. EMU Planetary Mineralogy (15): 33-65

Rubin AE (1997) Mineralogy of meteorite groups. Meteoritics \& Planetary Science (32):231-247

Shukoljukov Ju A, Pleshakov AM, Semjonova LF, Fisenko AA, Lavrova AD, Pustjakova AJu (1996)

He isotopic composition in diamond-bearing metamorphic rocks of N. Kazakhtan. Geokhimiya (1):22-35 (in Russian)

Tretiakova L (2010) Spectroscopic features due to Ni- and Co related defects in gem-quality natural diamonds. 20-th General Meeting, IMA, Hungary. Budapest 2010. Acta mineralogicalpetrographica abstract series (6):33

Yelisseyev A, Kanda H (2007) Optical Centers Related to 3d Transition Metals in Diamond. MY Tokio: New Diamond and Frontier Carbon Technology 17( 3):127-178

Zaitsev AM (2001) Optical properties of diamond. Berlin: Springer, pp 502 